\title{
Family caregiver burden: results of a longitudinal study of breast cancer patients and their principal caregivers
}

\author{
Eva Grunfeld, Doug Coyle, Timothy Whelan, Jennifer Clinch, Leonard Reyno, Craig C. Earle, \\ Andrew Willan, Raymond Viola, Marjorie Coristine, Teresa Janz, Robert Glossop
}

ß See related article page 1811

Abstract

Background: The vital role played by family caregivers in supporting dying cancer patients is well recognized, but the burden and economic impact on caregivers is poorly understood. We prospectively examined the psychosocial, occupational and economic impact of caring for a person with a terminal illness.

Methods: We studied 89 caregivers of women with advanced breast cancer receiving care at either the Ottawa or Hamilton regional cancer centres in Ontario. Patients were followed until their death or study completion at 3 years. Patients identified a principal caregiver to participate in the study. The Karnofsky Performance Status (KPS) index, the Medical Outcomes Study 36-item Short Form (SF-36), the Hospital Anxiety and Depression Scale, the Zarit Burden Inventory, FAMCARE and the Medical Outcomes Study Social Support Survey were administered during follow-up. Economic data were collected by means of a questionnaire administered by an interviewer. Assessments were conducted every 3 months during the palliative period (KPS score $>50$ ) and every 2 weeks during the terminal period (KPS score $\leq 50$ ).

Results: Over half of the caregivers were male (55\%) and the patient's spouse or partner (52\%), with a mean age of 53 years. At the start of the palliative period, the caregivers' mean physical functioning score was better than the patients' (51.3 v. 35.1, 95\% confidence interval $[\mathrm{Cl}]$ 13.3-20.0); there were similar mean mental functioning scores (46.6 and 47.1 respectively); similar proportions were depressed $(11 \%$ and $12 \%)$; and significantly more caregivers than patients were anxious (35\% v. 19\%, $p=0.009)$. More caregivers were depressed $(30 \%$ v. $9 \%, p=0.02)$ and had a higher level of perceived burden (26.2 v. 19.4, $p=0.02)$ at the start of the terminal period than at the start of the palliative period. Burden was the most important predictor of both anxiety and depression. Of employed caregivers, $69 \%$ reported some form of adverse impact on work. In the terminal period $77 \%$ reported missing work because of caregiving responsibilities. Prescription drugs were the most important component of financial burden.

Interpretation: Caregivers' depression and perceived burden increase as patients' functional status declines. Strategies are needed to help reduce the psychosocial, occupational and economic burden associated with caregiving.

CMAJ 2004;170(12):1795-801
$\mathrm{I}$ n Canada about 65000 people die each year as a result of cancer. ${ }^{1}$ The vital role played by family caregivers in supporting dying cancer patients is well recognized. ${ }^{2-7}$ With health care services being restructured and more cancer patients dying outside of hospital, ${ }^{8}$ the reliance on family caregivers to support patients with terminal illness at home is growing. ${ }^{9,10}$ However, the concern is that these caregivers may themselves be elderly or ill, or may be adult children with many other family and work responsibilities. ${ }^{11}$ To inform the growing public policy debate about family caregivers, ${ }^{2,9}$ we need a better understanding of who they are and how caregiving affects them. To this end we followed family caregivers of patients with advanced breast cancer and caregiver-patient pairs prospectively from the beginning of the patient's life-limiting illness through to terminal illness. We measured the psychosocial, occupational and economic impact of caregiving over the course of the patient's life-limiting illness, and compared the psychosocial impact of life-limiting illness on specific patient and caregiver pairs.

\section{Methods}

We selected patients with hormone refractory advanced breast cancer who were receiving care at either the Ottawa or Hamilton regional cancer centres and their principal family caregivers. The regional cancer centres are principal providers of tertiary cancer services in their respective regions. We enrolled 130 prospective eligible patients within 3 months of diagnosis of visceral metastases or hormone refractory uncontrollable local recurrence or bone metastases. Prospective eligible patients were identified by 2 methods: clinicians informed the research nurse when a patient meeting the eligibility criteria was seen in an outpatient clinic, and all outpatient clinic dictation notes were reviewed after each breast cancer clinic to identify eligible patients who may have been missed by the first method. Assessments were initially made every 3 months, and increased to every 2 weeks when the patients' functional status deteriorated (Karnofsky Performance Status [KPS] score $\leq 50) .{ }^{12-16}$ Data are reported for the palliative period (KPS score > 50) for all patients, and the terminal period for patients whose KPS score fell to 50 or lower. Participating patients were asked to identify a principal family caregiver, defined as a family member or friend who would be most responsible for ongoing caregiving. Of the 130 patients enrolled in the study, 89 identified a caregiver who consented to participate in the study. 
Consenting patients and their caregivers were followed prospectively until the patient's death or study completion, whichever came first. The study took place from October 1997 to October 2000. In this article we report the results for the 89 family caregivers who participated in the study. Ethical approval to conduct the study was obtained from the Ottawa Hospital and the McMaster University research ethics boards.

Caregiver and patient sociodemographic data were collected at the beginning of the study by means of a self-administered questionnaire. As summarized in the Appendix 1, standardized validated instruments were used to measure all domains. Caregiver general health status was measured by means of the Medical Outcomes Study 36-item Short Form (SF-36). ${ }^{1718}$ Psychological distress was measured by means of the Hospital Anxiety and Depression Scale (HADS). ${ }^{19-21}$ Family caregiver burden was measured by the Zarit Burden Inventory. ${ }^{22,23}$ Satisfaction with care was measured using the FAMCARE instrument, developed specifically to measure family satisfaction with palliative care. ${ }^{24,25}$ The Medical Outcomes Study (MOS) Social Support Survey was used to measure patient's social support. ${ }^{26}$

When the caregiver and patient pairs were compared, or caregivers were compared at 2 different time points (beginning of palliative period compared with end of palliative period; beginning of palliative period compared with beginning of terminal period), a matched pair $t$ test was used to compare means on quantitative variables, and McNemar's test was used to compare proportions on categorical variables. Fig. 1 summarizes the number of patients, caregivers and patient-caregiver pairs at each time point.

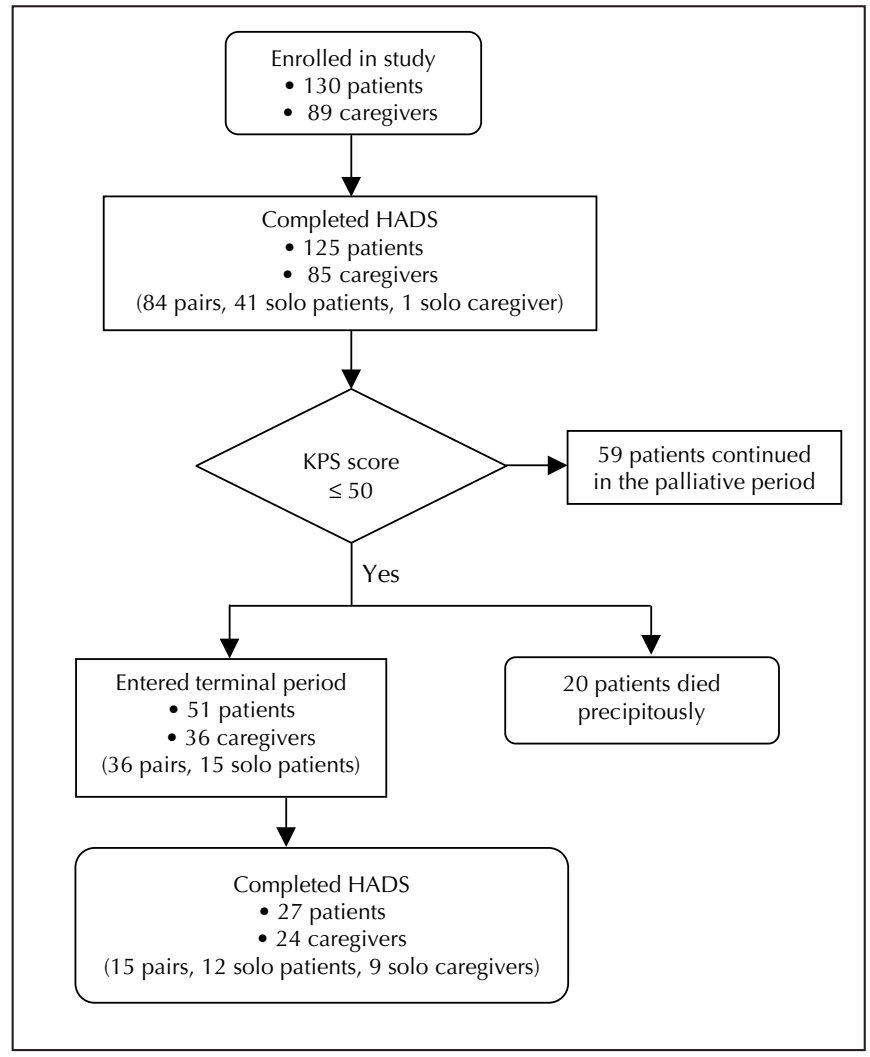

Fig. 1: Flow of patients and caregivers through study. HADS = Hospital Anxiety and Depression Scale, KPS = Karnofsky Performance Status.

All caregivers with 2 or more assessments in the palliative period $(n=67)$ had their first and last burden (Zarit Burden Inventory) and satisfaction with care (FAMCARE) scores compared using a paired $t$ test. Since the time interval between the 2 visits varied considerably (61-1023 days), which could have influenced the extent of change, a correlation coefficient was calculated between the change

Table 1: Characteristics of caregivers at the start of the palliative period $(n=89)$

\begin{tabular}{|c|c|}
\hline Characteristic & No. (\%) of caregivers* \\
\hline Age; mean (SD, range), yr & $52.8(15.2,19-82)$ \\
\hline Male & $49(55)$ \\
\hline Married & $66(74)$ \\
\hline \multicolumn{2}{|l|}{ Education } \\
\hline College or university & $57(64)$ \\
\hline No postsecondary & $27(30)$ \\
\hline \multicolumn{2}{|l|}{ Employment status } \\
\hline Employed, full- or part-time & $50(56)$ \\
\hline Retired & $24(27)$ \\
\hline Stopped working because of caregiving & $2(2)$ \\
\hline Other & $15(17)$ \\
\hline Missed work because of caregiving & $40(69) \dagger$ \\
\hline \multicolumn{2}{|l|}{ Occupation } \\
\hline Professional & $35(39)$ \\
\hline Managerial & $18(20)$ \\
\hline Other & $36(40)$ \\
\hline Involved in religious activities & $36(40)$ \\
\hline Participated in support group & $4(5)$ \\
\hline Had $\geq 1$ dependent at home & $34(38)$ \\
\hline \multicolumn{2}{|l|}{ Relationship to patient } \\
\hline Spouse or partner & $46(52)$ \\
\hline Sister or daughter & $26(29)$ \\
\hline Friend & $6(7)$ \\
\hline Other & $11(12)$ \\
\hline \multicolumn{2}{|l|}{ Proximity to patient } \\
\hline Lives in same house & $59(66)$ \\
\hline Lives nearby & $10(12)$ \\
\hline Lives $>1$ h drive away & $20(23)$ \\
\hline \multicolumn{2}{|l|}{ Health status, mean score (SD) $\ddagger$} \\
\hline Social functioning & $87.1(18.5)$ \\
\hline Physical functioning & $87.5(17.8)$ \\
\hline Role functioning, physical & $77.1(37.6)$ \\
\hline Role functioning, emotional & $70.0(38.6)$ \\
\hline General health & $70.3(21.4)$ \\
\hline Pain & $75.9(18.5)$ \\
\hline Vitality & $57.0(21.0)$ \\
\hline Mental health & $68.5(19.4)$ \\
\hline Satisfaction with care, mean score (SD) $\ddagger$ & 79.3 (14.9) \\
\hline Caregiver burden, mean score (SD) $\ddagger$ & $18.3(11.6)$ \\
\hline \multicolumn{2}{|l|}{ Psychological distress, mean score (SD) $\ddagger$} \\
\hline Anxiety & $8.3(4.3)$ \\
\hline Depression & $5.1(4.0)$ \\
\hline
\end{tabular}


scores of each scale and the visit intervals: neither correlation was significant $(r=0.06, p=0.63$, and $r=0.05, p=0.67$, respectively).

We used stepwise multiple regression analyses to construct 2 models for the prediction of caregiver anxiety and depression as measured by the HADS subscales at the start of the palliative period. Candidate predictor variables for caregiver anxiety were patient's KPS score, HADS anxiety and depression scores, SF-36 physical and mental component scores, caregiver's age, Zarit Burden Inventory score and MOS emotional support subscale. For caregiver depression, all the same variables were included, except the caregiver's SF-36 physical component score was excluded and the caregiver's participation in religious or spiritual activities was included. Only variables showing a univariate association with $p$ less than or equal to 0.15 were used in the regression analysis.

Direct financial burden to the patient or caregiver consisting of both direct treatment and nontreatment costs was obtained through interviewer-administered questionnaires at each assessment. We assumed that patients with extended health coverage (88/130 [68\%]) were not responsible for expenses such as prescription drugs or private hospital rooms. The cost of individual resource items were either obtained directly from the participant or through standard resource valuation measures. ${ }^{27}$

Financial burden is presented as both a weekly estimate for the palliative and terminal periods and as a cumulative burden over the entire study period.

\section{Results}

Caregivers were, on average, younger than the patients (52.8 years [range 19-82] v. 56.2 years [range 26-83]). Just over half were male $(55 \%)$ and the patient's spouse or partner $(52 \%)$ (Table 1). The rest were female relatives (29\%) or friends $(7 \%)$.
There were no significant differences between the patients with a caregiver enrolled in the study and the $41 \mathrm{pa}-$ tients who did not have a caregiver enrolled in the study with respect to baseline characteristics (age, education, income, marital status or living alone) (data not shown).

A comparison of patient and caregiver pairs at the start of the palliative and terminal periods is shown in Table 2 . For the palliative period, the mean caregiver's physical functioning score was better than the mean patient's physical functioning score $(51.3$ v. 35.1 ; $95 \%$ CI $13.3-20.0$, $p<0.001)$. Similar proportions of caregivers $(11 \%)$ and patients $(12 \%)$ were depressed. Significantly more caregivers than patients were anxious, as reflected by both mean scores $(8.4 \mathrm{v} .7 .3, p=0.03)$ and proportion of cases $(35 \% \mathrm{v}$. $19 \%, p=0.009)$.

The findings were similar for the terminal period. Significantly more caregivers than patients were anxious, as reflected by both mean scores $(9.9$ v. $6.8, p=0.01)$ and proportion of cases $(40 \%$ v. $27 \%, p=0.4)$, although cases did not reach significance.

\section{Psychological impact}

At the start of the palliative period, the mean score of caregiver burden was 18.3 (Table 1) and did not change significantly during the entire palliative period $(p=0.45)$. Satisfaction with care was high and increased significantly during the palliative period, from a mean score of 79.3 (standard deviation [SD] 14.9) to 83.4 (SD 11.2) $(p=0.04)$.

The impact over time on the caregivers of 24 patients who reached the terminal period is presented in Table 3 .

\begin{tabular}{|c|c|c|c|c|}
\hline Characteristic & Caregivers & Patients & Difference $(95 \% \mathrm{Cl})$ & $p$ value \\
\hline \multicolumn{5}{|l|}{ Start of palliative period $(n=84)^{*}$} \\
\hline Physical summary score, $\uparrow$ mean $(\mathrm{SD}) \ddagger$ & $51.3(9.7)$ & $35.1(12.4)$ & $-16.2(-20.0$ to 13.3$)$ & $<0.001$ \\
\hline Mental summary score, $\uparrow$ mean $(\mathrm{SD}) \ddagger$ & $46.6(12.0)$ & $47.1(11.2)$ & $0.5(-2.5$ to 3.1$)$ & 0.8 \\
\hline \multicolumn{5}{|l|}{ Anxiety, $\S$} \\
\hline Mean score $(\mathrm{SD}) \ddagger$ & $8.4(4.3)$ & $7.3(4.1)$ & $-1.1(-2.2$ to 0.1$)$ & 0.03 \\
\hline No. of cases $(\%)$ & $29(35)$ & 16 (19) & - & 0.009 \\
\hline \multicolumn{5}{|l|}{ Depression, $\$$} \\
\hline Mean score $(\mathrm{SD}) \ddagger$ & $5.1(3.9)$ & $5.2(4.2)$ & $0.12(-0.94$ to 1.18$)$ & 0.82 \\
\hline No. $(\%)$ of cases & $9 \quad(11)$ & $10 \quad(12)$ & - & 0.79 \\
\hline \multicolumn{5}{|l|}{ Start of terminal period $(n=15)^{*}$} \\
\hline \multicolumn{5}{|l|}{ Anxiety } \\
\hline Mean score $(\mathrm{SD}) \neq$ & $9.9(3.0)$ & $6.8(4.4)$ & $-3.05(-5.3$ to -0.8$)$ & 0.01 \\
\hline No. $(\%)$ of cases & $6 \quad(40)$ & $4 \quad(27)$ & - & 0.4 \\
\hline \multicolumn{5}{|l|}{ Depression } \\
\hline Mean score $(\mathrm{SD}) \ddagger$ & $7.7(4.3)$ & $8.1(3.4)$ & $0.4(-1.9$ to 2.8$)$ & 0.7 \\
\hline No. $(\%)$ of cases & $4 \quad(27)$ & $4 \quad(27)$ & - & 1.0 \\
\hline
\end{tabular}


Similar proportions of these caregivers were anxious at the start of the terminal period as at the start of the palliative period $(39 \%$ v. $35 \%, p=0.18)$. More of these caregivers were depressed $(30 \%$ v. $9 \%, p=0.02)$ and experienced a higher level of burden (mean score $26.2 \mathrm{v} .19 .4, p=0.02$ ) at the start of the terminal period than at the start of the palliative period.

Predictors of caregiver anxiety and depression at the start of the palliative period are shown in Table 4. Caregiver burden was the most important predictor of both anxiety and depression.

\section{Occupational impact}

At the start of the palliative period, about half of the caregivers $(56 \%)$ were in full- or part-time employment and about one quarter $(27 \%)$ were retired. In the paired comparison between employed caregivers who moved from the palliative period to the terminal period $(n=17)$, there was no change in employment status: they did not quit, lose or change their jobs (data not shown). However, more caregivers missed work in the terminal period than in the palliative period $(77 \%$ v. $53 \%, p=0.04)$. Caregivers also reported an increased inability to work regular hours and increased hours of work lost in the terminal period because of care provided (Table 3).

\section{Economic impact}

Prescription drugs were, on average, the most significant component of financial burden (Table 5). The average financial burden born by families (either the caregiver or pa- tient) during the patient's illness was higher for those without extended health insurance $(n=42, \$ 8292$ [SD \$7235]) than for those with extended health insurance coverage $(n=88, \$ 5765[\mathrm{SD} \$ 8926])(p=0.04)$.

\section{Interpretation}

In our longitudinal study, we found that caregivers experienced substantial psychological morbidity (anxiety and depression) at the onset of the patient's palliative illness and a substantial increase in caregiver burden and depression when the patient reached a terminal stage of the illness. In addition to psychological morbidity, caregivers bore both economic and occupational burdens.

Our finding that caregiver's psychological morbidity was equal to or greater than the patient's is consistent with other research..$^{28-35}$ The finding that a large proportion of caregivers suffered from both anxiety and depression suggests that there are unmet needs that are measurable at an early stage of the patient's life-limiting illness, and points to the need for early psychological assessment and potential intervention. ${ }^{36}$ Our research with a subset of these same caregivers during their bereavement suggests that they are so focused on their caregiving role that their own medical needs go unattended, ${ }^{37}$ as has been found in other studies. ${ }^{38}$ Our findings indicate that, although patient's physical and emotional factors predict caregiver distress, perceived burden is the strongest predictor of caregiver anxiety and depression. In previous research feelings of burden have been found to be associated with anxiety in daughters of patients with cancer ${ }^{39}$ and caregivers of patients with dementia. ${ }^{35}$

\begin{tabular}{|c|c|c|c|c|}
\hline Characteristic & $\begin{array}{c}\text { Start of } \\
\text { palliative period }\end{array}$ & $\begin{array}{c}\text { Start of } \\
\text { terminal period }\end{array}$ & $\begin{array}{l}\text { Difference } \\
(95 \% \mathrm{Cl})\end{array}$ & $p$ value \\
\hline \multicolumn{5}{|l|}{ Anxiety } \\
\hline Mean score $(\mathrm{SD}) \dagger$ & $8.8(4.1)$ & $10.2(3.2)$ & $-1.3(-3.2$ to 0.5$)$ & 0.15 \\
\hline No. (\%) of casesł & $8(35)$ & $9.0(39.1)$ & & 0.18 \\
\hline \multicolumn{5}{|l|}{ Depression } \\
\hline Mean score $(\mathrm{SD}) \dagger$ & $5.2(3.8)$ & $8.1(4.9)$ & $-2.9(-4.6$ to -1.2$)$ & 0.002 \\
\hline No. (\%) of casesł & $2(9)$ & $7(30)$ & & 0.02 \\
\hline Caregiver burden, mean score $(\mathrm{SD}) \dagger$ & $19.4(12.9)$ & $26.2(12.4)$ & $-6.8(-12.7$ to -0.9$)$ & 0.02 \\
\hline Satisfaction with care, mean score (SD) $\dagger$ & $82.1(9.7)$ & $80.6(10.8)$ & $1.5(-3.1$ to 6.1$)$ & 0.7 \\
\hline \multicolumn{5}{|l|}{ Impact on work $(n=17) \S$} \\
\hline Missed work, no. (\%) & $9(53)$ & $13(76)$ & - & 0.04 \\
\hline Left work for appointments, no. (\%) & $8(47)$ & $9(53)$ & - & 0.65 \\
\hline Received interrupting phone calls, no. (\%) & $4(24)$ & $7(41)$ & - & 0.08 \\
\hline Used holidays or special leave, no. $(\%)$ & $6(35)$ & $7(41)$ & - & 0.56 \\
\hline Decreased work hours, no. (\%) & $4(24)$ & $9(53)$ & - & 0.02 \\
\hline Hours of work lost, $\uparrow$ mean (SD)† & $6.1(12.4)$ & $11.4(15.9)$ & $-5.4(-10.0$ to -0.7$)$ & 0.03 \\
\hline
\end{tabular}


Our finding that a majority of caregivers experienced an adverse impact on their employment, particularly during the terminal period, is consistent with the results of the 1996 General Social Survey ${ }^{40}$ and other studies of family caregivers of cancer patients..$^{14,41-44}$ In our study, $5 \%$ of caregivers had quit their job or declined advancement,

Table 4: Predictors of caregiver's psychological distress at the start of the palliative period

\begin{tabular}{lcc}
\hline Predictor & $\begin{array}{c}\text { Raw regression }(\beta) \\
\text { coefficient* }\end{array}$ & $p$ value \\
\hline For caregiver anxiety & 0.16 & $<0.001$ \\
$\quad$ Caregiver burden & 0.23 & 0.03 \\
Patient's anxiety & -0.07 & 0.03 \\
Patient's physical functioning $\dagger$ & & \\
For caregiver depression & 0.2 & $<0.001$ \\
Caregiver burden & -1.06 & 0.03 \\
Patient's emotional support &
\end{tabular}

* $\beta$ coefficients indicate the extent to which anxiety or depression increase (positive coefficients) or decrease (negative coefficients) by an increase of 1 unit in the predictor (e.g., if the Zarit burden score increases by 1 , the caregiver's anxiety will increase by 0.16 all other predictors remaining constant).

†As measured by the SF-36 Physical Component Score. Patient's worsening physical functioning is a predictor for caregiver anxiety. and a large proportion lost work hours or used special leave or holidays to fulfill their caregiving responsibilities. The Senate report on end-of-life care ${ }^{2}$ recommends income security and job protection for family members who care for people who are dying. Our finding underscores the importance of implementing this recommendation. Similarly, our finding of significant costs of prescription drugs - particularly for those without extended health insurance - supports the need for a policy that addresses the growing impact of drug costs on patients and their families, as recommended by the National Forum on Health $^{45}$ and the Romanow report. ${ }^{46}$

Our study has limitations. The complexity and challenges of conducting palliative care research are well recognized..$^{47,48}$ Although we began with 89 caregivers at the outset of the palliative period, only 36 had patients who entered the terminal period, either because the patient died before we were able to document (KPS score $\leq 50)$ or because the patient's functional status remained high (KPS score $>50$ ) throughout the study. This might have limited our power to detect real but small changes over time.

A further limitation of the study is that it involved an urban, relatively well-educated group of caregivers. Few patients in this study lived alone, and even those who did

Table 5: Economic burden per patient, by period

\begin{tabular}{|c|c|c|c|}
\hline \multirow[b]{2}{*}{ Expense } & \multicolumn{2}{|c|}{ Weekly burden, mean (SD), \$ } & \multirow{2}{*}{$\begin{array}{c}\text { Cumulative burden, } \\
\text { mean (SD), } \$ \\
n=130\end{array}$} \\
\hline & $\begin{array}{l}\text { Palliative period } \\
\quad n=130\end{array}$ & $\begin{array}{c}\text { Terminal period } \\
\quad n=51\end{array}$ & \\
\hline Prescription drugs & $25.5(60.1)$ & $25.0(45.2)$ & $1402.4(3298.3)$ \\
\hline IQR & 0-18 & $0-38$ & 0-1227 \\
\hline Home help & $11.1(46.4)$ & $5.3(26.8)$ & $946.2(4931.5)$ \\
\hline IQR & 0-0 & $0-0$ & $0-0$ \\
\hline Food & $13.0(18.5)$ & $16.5(25.3)$ & $841.0(1289.9)$ \\
\hline IQR & 0-18 & $0-26$ & 36-1085 \\
\hline Travel & $9.6(8.6)$ & $14.9(18.8)$ & $661.7(703.9)$ \\
\hline IQR & $3-14$ & $1-18$ & 176-1023 \\
\hline Furniture and modifications & $7.8(41.4)$ & $25.7(92.1)$ & $611.1(2795.4)$ \\
\hline IQR & 0-0 & 0-0 & 0-83 \\
\hline Alternative medicines & $11.0(40.0)$ & $2.8(13.6)$ & $536.1(1345.2)$ \\
\hline IQR & $0-5$ & 0-0 & $0-322$ \\
\hline Alternative therapies & $11.5(41.9)$ & $2.8(11.8)$ & $531.6(1468.4)$ \\
\hline IQR & $0-3$ & $0-0$ & 0-190 \\
\hline Over-the-counter medicines & $1.6(2.2)$ & $2.1(4.0)$ & $116.0(166.5)$ \\
\hline IQR & $0-2$ & $0-3$ & $16-135$ \\
\hline Accommodation & $1.4(8.1)$ & $29.1(157.3)$ & $140.1(815.6)$ \\
\hline IQR & $0-0$ & 0-0 & 0-0 \\
\hline Private nurse & $0.9(6.3)$ & $1.0(7.5)$ & $64.9(400.8)$ \\
\hline IQR & 0-0 & 0-0 & 0-0 \\
\hline Child care & $0.7(5.2)$ & $1.9(9.7)$ & $46.0(365.0)$ \\
\hline IQR & 0-0 & 0-0 & $0-0$ \\
\hline Other expenses & $11.5(41.8)$ & $14.3(60.9)$ & $670.9(2097.1)$ \\
\hline IQR & 0-4 & 0-0 & 0-389 \\
\hline \multirow[t]{2}{*}{ Total } & $105.8(138.56)$ & $141.6(215.0)$ & $6581.6(8472.5)$ \\
\hline & $27-114$ & $12-134$ & 1879-7317 \\
\hline
\end{tabular}

Note: IQR = interquartile range 
live alone had a caregiver. In fact we found no differences on baseline variables between patients who had a caregiver enrolled in the study and those who did not. Thus, it is likely that all of the patients in the cohort had a caregiver involved in their care, despite the enrolment of only $68 \%$ of the caregivers. Although there were no differences between patients with and those without an enrolled caregiver, we are unable to determine whether there were any systematic differences between caregivers who consented to participate in this study and those who did not.

We have documented substantial psychological, occupational and economic burdens associated with caregiving at the outset of life-limiting illness that increase as patients' functional status declines and death approaches. Caregiver burden was the most important predictor of both caregiver anxiety and depression. We have reported the positive aspects of caregiving expressed by a subset of these caregivers. ${ }^{37}$ In that report we stated that the caregiver's commitment to the patient had primacy over his or her own occupational and health concerns. The changes to Canada's health care system - fewer acute care and palliative care in-patient beds $s^{8}$ - will result in an increased dependence on family caregivers to support dying cancer patients. Strategies to support caregivers, as recommended by the Senate report on end-of-life care, ${ }^{2,49}$ would reduce caregiver burden, potentially prevent psychosocial distress and allow caregivers to focus on their most immediate concern, caring for the dying patient. ${ }^{37}$

\section{This article has been peer reviewed.}

From the Ottawa Regional Cancer Centre and Division of Medical Oncology, University of Ottawa (Grunfeld), the Clinical Epidemiology Program, Ottawa Health Research Institute, Ottawa Hospital (Grunfeld, Coyle, Clinch, Viola, Coristine, Janz), the Institute of Palliative Care, Elizabeth Bruyère Health Centre (Viola) and the Vanier Institute of the Family (Glossop), Ottawa, Ont.; the Supportive Cancer Care Research Unit (Grunfeld, Whelan, Reyno, Willan), and the Hamilton Regional Cancer Centre and Division of Radiation Oncology (Whelan), McMaster University, and the Center for the Evaluation of Medicine, St. Joseph's Hospital (Willan), Hamilton, Ont.; the Division of Medical Oncology, Dalhousie University, Halifax, NS (Grunfeld, Reyno); and the Center for Outcomes and Policy Research and Department of Adult Oncology, Dana-Farber Cancer Institute, Harvard Medical School, Boston, Mass. (Earle)

Contributors: Eva Grunfeld was principally responsible for the development of the protocol, all aspects of ongoing study management, analysis of the data and writing of the manuscript. Doug Coyle, Timothy Whelan, Leonard Reyno, Craig Earle and Raymond Viola contributed to the development of the protocol, interpretation of the analysis and review of the manuscript. Marjorie Coristine contributed to the study design and ongoing study management. Doug Coyle was responsible for all aspects of the economic analysis. Andrew Willan was responsible for construction of the database. Andrew Willan and Jennifer Clinch oversaw the analysis. Jennifer Clinch and Teresa Janz conducted the analysis. Robert Glossop contributed to the development of the protocol, interpretation of the results and review of the manuscript. All authors reviewed the manuscript and approved the final version.

Competing Interests: None declared.

Acknowledgements: We would like to acknowledge with gratitude the women and family caregivers who participated in this study. Their dedication to the study and willingness to be interviewed under very stressful circumstances, for the sake of helping other women with breast cancer and those who care for them, were inspiring. The study was funded by the Canadian Breast Cancer Research Alliance (grant 008026) with support from the Ontario Ministry of Health and Long-term Care (grant 04171)

\section{References}

1. National Cancer Institute of Canada. Canadian Cancer Statistics 2002. Toronto: National Cancer Institute of Canada; 2002. p. 1-96.

2. Subcommittee of the Standing Senate Committee on Social Affairs, Science and Technology. Quality end-of-life care: the right of every Canadian. Ottawa: The Senate of Canada; 2000. Available: www.parl.gc.ca/36/2/parlbus/commbus /senate/Com-e/upda-e/rep-e/repfinjun00-e.htm (accessed 2004 Feb 17).

3. McWhinney IR, Bass MJ, Orr V. Factors associated with location of death (home or hospital) of patients referred to a palliative care team. CMAf 1995; 152(3):361-7.

4. Townsend J, Frank AO, Fermont D, Dyer S, Karran O, Walgrove A, et al Terminal cancer care and patients' preference for place of death: a prospective study. BM7 1990;301(6749):415-7.

5. Howarth G, Willison KB. Preventing crises in palliative care in the home. Role of family physicians and nurses. Can Fam Physician 1995;41:439-45.

6. Chappell NL. Home care research: What does it tell us? Gerontologist 1994; 34:116-20.

7. Zimmer JG, Groth-Juncker A, McCusker J. A randomized controlled study of a home health care team. Am f Public Health 1985;75:134-41.

8. Burge F, Lawson B, Johnston G. Trends in the place of death of cancer patients, 1992-1997. CMA7 2003;168(3):265-70.

9. Keating NC, Fast JE. Bridging policy and research in eldercare. Can $\mathcal{F}$ Aging 1997;16:S22-S41.

10. Houts P, Nezu AM, Maguth Nezu C, Bucher JA. The prepared family caregiver: a problem-solving approach to family caregiver education. Patient Educ Couns 1996;27:63-73.

11. Grunfeld E, Glossop R, McDowell I, Danbrook C. Caring for elderly people at home: the consequences to caregivers. CMA7 1997;157(8):1101-5.

12. Morris JN, Sherwood S. Quality of life of cancer patients at different stages in the disease trajectory. 7 Chronic Dis 1987;40:545-53.

13. Mor V. Assessing patient outcomes in hospice: what to measure? Hosp 71986 2:17-35.

14. Addington-Hall JM, MacDonald LD, Chamberlain J, Freeling P, Bland JM, Raferty J. Randomized controlled trial of effects of coordinating care for terminally ill cancer patients. BM7 1992;305:1317-22.

15. Mor V, Laliberte L, Morris JN, Wiemann M. The Karnofsky Performance Status Scale. An examination of its reliability and validity in a research setting. Cancer 1984;53:2002-7.

16. Morris JN, Suissa S, Sherwood S, Wright SM, Greer D. Last days: a study of the quality of life of terminally ill cancer patients. 7 Chronic Dis 1986;39:47-62.

17. Ware JE, Snow KK, Kosinski M, Gandek B. SF-36 health survey manual and interpretation guide. Boston: The Health Institute, New England Medical Center; 1993.

18. Ware JE, Kosinski M, Keller SD. SF-36 Physical and Mental Health Summary Scales: a user's manual. Boston: The Health Institute, New England Medical Center; 1994.

19. Zigmond AS, Snaith RP. The hospital anxiety and depression scale. Acta Psychiatr Scand 1983;67:361-70.

20. Zung WWK. A rating instrument for anxiety disorders. Psychosomatics 1971; 12:371-9.

21. Lewis G, Wessely S. Comparison of the General Health Questionnaire and the Hospital Anxiety and Depression Scale. Br F Psychiatry 1990;157:860-4.

22. Zarit SH, Reever KE, Bach-Peterson J. Relatives of the impaired elderly: correlates of feelings of burden. Gerontologist 1980;20:649-55.

23. Zarit SH, Todd PA, Zarit JM. Subjective burden of husbands and wives as caregivers: a longitudinal study. Gerontologist 1986;26:260-6.

24. Kristjanson L. Validity and reliability testing of the FAMCARE scale: measuring family satisfaction with advanced cancer care. Soc Sci Med 1993;36:693-701.

25. Kristjanson LJ. Indicators of quality of palliative care from a family perspective. $\mathcal{F}$ Palliat Care 1986;1:8-17.

26. Sherbourne CD, Stewart AL. The MOS Social Support Survey. Soc Sci Med 1991;32:705-14.

27. Institute of Health Economics. A national list of provincial costs for health care: Canada, 1997/8. Available: www.ihe.ca/download/national_costlist.pdf (accessed 2004 Feb 17)

28. Weitzner MA, McMillan SC, Jacobsen PB. Family caregiver quality of life differences between curative and palliative cancer treatment settings. 7 Pain Symptom Manage 1999;17:418-28.

29. Cassileth BR, Lusk EJ, Strouse TB, Miller DS, Brown LL, Cross PA. A psychological analysis of cancer patients and their next-of-kin. Cancer 1985;55:72-6.

30. Baumgarten $M$. The health of persons giving care to the demented elderly: a critical review of the literature. 7 Clin Epidemiol 1989;42:1137-48.

31. McMillan SC. Quality of life of primary caregivers of hospice patients with cancer. Cancer Pract 1996;4:191-8.

32. Nijboer C, Tempelaar R, Sanderman R, Triemstra M, Spruijt RJ, van den Bos GA. Cancer and caregiving: the impact on the caregiver's health. Psychooncology 1998;7:3-13.

33. Hinton J. Can home care maintain an acceptable quality of life for patients with terminal cancer and their relatives? Palliat Med 1994;8:183-96. 
34. Hinds C. The needs of families who care for patients with cancer at home: are we meeting them? 7 Adv Nurs 1985;10:575-81.

35. Chappell NL, Penning M. Behavioural problems and distress among caregivers of people with dementia. Ageing Soc 1996;16:57-73.

36. Kelly B, Edwards P, Synott R, Neil C, Baillie R, Battistutta D. Predictors of bereavement outcome for family carers of cancer patients. Psychooncology 1999; 8:237-49.

37. Coristine M, Crooks D, Grunfeld E, Stonebridge C, Christie A. Caregiving for women with advanced breast cancer. Psychooncology 2003;12:709-19.

38. Schulz R, Beach SR. Caregiving as a risk factor for mortality: the caregiver health effects study. FAMA 1999;282:2215-9.

39. Raveis VH, Karus D, Pretter S. Correlates of anxiety among adult daughter caregivers to a parent with cancer. 7 Psychosoc Oncol 1999;17:1-26.

40. Cranswick K. Canada's caregivers. Canadian social trends backgrounder. Ottawa: Statistics Canada; 2001. Available: www.hc-sc.gc.ca/seniors-aines/pubs /unsorted/survey.htm (accessed 2004 Feb 17).

41. Stommel M, Given CW, Given BA. The cost of cancer home care to families. Cancer 1993;71:1867-74.

42. Hayman JA, Langa KM, Kabeto MU. Estimating the cost of informal caregiving for elderly patients with cancer. 7 Clin Oncol 2001;19:3219-25.

43. Philp I, McKee KJ, Meldrum P. Community care for demented and nondemented elderly people: a comparison study of financial burden, service use, and unmet needs in family supporters. BM7 1995;310:1503-6.
44. Covinsky KE, Goldman L, Cook EF. The impact of serious illness on patients' families. 7AMA 1994;272:1839-44.

45. National Forum on Health. Canada Health Action: Building on the legacy. Volume 1. The Final Report. Ottawa: Health Canada; 1997. Available: www.hc-sc .gc.ca/english/care/health_forum/forum_e.htm (accessed 2004 Feb 17).

46. Health Canada. Commission on the Future of Health Care in Canada. Final Re port. Ottawa: Health Canada; 2002. Available: www.hc-sc.gc.ca/english/care /romanow/hcc0086.html (accessed 2004 Feb 17).

47. McWhinney IR, Bass MJ, Donner A. Evaluation of palliative care service: problems and pitfalls. BM7 1994;309:1340-2.

48. Cohen SR, Bultz BD, Clarke J, Kuhl DR, Poulson MJ, Baldwin MK, et al Well-being at the end of life: Part 1 . A research agenda for psychosocial and spiritual aspects of care from the patient's perspective. Cancer Prev Control 1997;1(5):333-42.

49. Chochinov HM. The Senate report on end-of-life care: the ball is in our court. CMA7 2001;164(6):794-5.

Correspondence to: Eva Grunfeld, Cancer Care Nova Scotia,

1278 Tower Rd., Bethune Building, Halifax NS B3H 2Y9;

Eva.Grunfeld@ccns.nshealth.ca

\begin{tabular}{|c|c|c|}
\hline \multicolumn{3}{|c|}{ Appendix 1: Measurement instruments } \\
\hline Domain and instrument & Properties (score range) & Administered \\
\hline \multicolumn{3}{|l|}{ Functional status } \\
\hline Karnfosky Performance & $(0-100)$ & Patient \\
\hline Status $^{15,16^{\prime}}$ & $\begin{array}{l}\text { - Higher score means better } \\
\text { performance status }\end{array}$ & $\begin{array}{l}\text { - Every } 3 \mathrm{mo} \text { in palliative period } \\
\text { - Every } 2 \mathrm{wk} \text { in terminal period }\end{array}$ \\
\hline \multicolumn{3}{|l|}{ General health status } \\
\hline SF-36 $6^{17,18}$ & $\begin{array}{l}\text { (0-100) } \\
\text { - Higher score means better health } \\
\text { - } 8 \text { subscales } \\
\text { - Physical Component Score } \\
\text { - Mental Component Score }\end{array}$ & $\begin{array}{l}\text { Caregiver and patient } \\
\text { - Start of palliative period }\end{array}$ \\
\hline \multicolumn{3}{|l|}{ Psychological distress } \\
\hline Hospital Anxiety and & $(0-21)$ & Caregiver and patient \\
\hline Depressions Scale ${ }^{19-21}$ & $\begin{array}{l}\text { - } 2 \text { subscales } \\
\text { - Clinical anxiety (HADS score } \geq 11 \text { ) } \\
\text { - Clinical depression (HADS score } \geq 11 \text { ) }\end{array}$ & $\begin{array}{l}\text { - Start of palliative period } \\
\text { - Start of terminal period }\end{array}$ \\
\hline \multicolumn{3}{|l|}{ Caregiver burden } \\
\hline Zarit Burden Inventory ${ }^{22,23}$ & $\begin{array}{l}(0-88) \\
\text { - Higher score means greater burden }\end{array}$ & $\begin{array}{l}\text { Caregiver } \\
\text { - Every } 3 \mathrm{mo} \text { in palliative period } \\
\text { - Every } 2 \mathrm{wk} \text { in terminal period }\end{array}$ \\
\hline \multicolumn{3}{|l|}{ Satisfaction with care } \\
\hline FAMCARE 24,25 & $\begin{array}{l}\text { (20-100) } \\
\text { - Higher score means more satisfied }\end{array}$ & $\begin{array}{l}\text { Caregiver } \\
\text { - Every } 3 \mathrm{mo} \text { in palliative period } \\
\text { - Every } 2 \mathrm{wk} \text { in terminal period }\end{array}$ \\
\hline \multicolumn{3}{|l|}{ Social support } \\
\hline MOS Social Support Survey ${ }^{26}$ & $\begin{array}{l}(0-100) \\
\text { - } 4 \text { subscales (e.g., emotional support) } \\
\text { - Higher score means greater support }\end{array}$ & $\begin{array}{l}\text { Patient } \\
\text { - Start of palliative period }\end{array}$ \\
\hline
\end{tabular}

